\title{
The Development of Thematic Mathematics Book Based on Environment with a Realistic Approach to Implant the Attitude of Caring about Environment at Students of Elementary School Grade One in Kupang
}

\author{
Ch. Krisnandari Ekowati ${ }^{1}$ \& Juliana M. H. Nenohai ${ }^{1}$ \\ ${ }^{1}$ Department of Mathematics Education, Faculty of Education Nusa Cendana University, Indonesia \\ Correspondence: Ch. Krisnandari Ekowati, Department of Mathematics Education, Faculty of Education Nusa \\ Cendana University, Indonesia.
}

Received: November 5, 2016

Accepted: November 23, 2016

Online Published: November 30, 2016

doi:10.5430/ijhe.v6n1p112

URL: http://dx.doi.org/10.5430/ijhe.v6n1p112

\begin{abstract}
The backdrop of this research is among others (1) the content of article 8 legislation national education system 20/2003 that the society takes the participation in planning and evaluating education, (2) the criterion of curriculum 2013 that is integrated and has a theme of natural environment, (3) the reality in the field showing that mathematics is not too meaningful, (4) do not use the school environment yet in outdoor learning so that can implant the attitude of caring about the envoronment. Based on the backdrop, the problem statement of this research is: how to develop thematic mathematics book based on environment with a realistic approach to implant the attitude of caring about the environment at the students of elementary school grade one in Kupang as early as possible?

The method used is Research and Development with a type of Formative Research introduced by Tessmer in 1993. There are three steps in this research among others (1) the step of getting early data by using survey method analysed descriptively, (2) the step of developing the thematic mathematics books validated by the expert of education and mathematics (3) experiment step that is analysed with an inferensial statistic by using dependent $t$ correlation analysis to know the difference of the student's mathematics knowledge before and after using the learning tool developed and to implant the attitude of caring about the environment at the students.

The school used as the limited class test or small class test toward the product developed is Directive Primary School Naimata Kupang, meanwhile for the big class test is Catholic Primary School St. Arnoldus Kupang. The basic reason to choose both of the schools is the minimum of reference books used by the teachers at grade one at the schools, and they do not use the large area of the schools field as a medium in learning.

The result of the research based on the problem statement showing that almost all the students is very active and have a positive response. The attitude of caring about the environment begin to appear after using the thematic mathematics book developed, as a guide book for the teachers and the practice book for the students. Besides, the students' understanding toward the number basic concept, the number operations and the two dimensions also increase and the misconception doesn't occur.
\end{abstract}

Keywords: Research and Development, Thematic of Mathematics, Realistic Mathematics Education, Environmentally Conscious Attitude

\section{Introduction}

Almost all of Indonesian society is of the opinion that the responsibility of children education is only the duty of the teachers in the school, so that the parents just have a very little attention about it. This condition is very contradictive with the sound of article 8 part three legislation national education system 20/2003 saying that the society has the right in participating, implementation, supervision, and evaluation of education program. Therefore, the suggestion from the parents toward the learning in the school is needed by the school side, especially about the problem of tools and infrastructures to support the learning by the teacher in the class.

Mathematics is one of the lessons being afraid by almost all of the students from elementary school until senior high school students. This condition is caused by several reasons, among others (1) the problem that the material learnt is 
full of numbers that always makes the students confuse, (2) the problem of learning approach choice that is not too good for the studnts so that they feel boring, (3) the problem of mathemathics teacher itself that tends not to be close to the students (Christine Ekowati, 2003).

Whereas mathematics as one of the lessons taught in the school that has a very important position, since it can give the ability to solve the problems and the ability to think logically as well (Purnama Dewi, 2011). Teaching mathematics is not too easy since the fact showing that the students undergo difficulties to study mathematics (Jaworski in the Ministry for Education, 2003:2). The difficulties can be viewed in solving the mathematical problem. In relevance to this problem the searching of the students' difficulties in solving the mathematical problem is done by detecting the students' error in studying mathematics. Soedjadi, et all (1996: 1) saying that the difficulties is the main reason of the error.

The age of elementary school students is an age where they are still at the age of thinking concretely (the step of concrete operation, Jean Piaget), so that mathematics that is full of formulations will be very boring and never be liked by the students if it is not applied in daily life (Christine K. Ekowati, 2006). The other reason is the implementation of learning in the class is still convensional, where the teacher just introduce the formulations and then it will be continued by the practice to solve the fictitious problems (just about the numbers) without explaining the function or the relationship with the real life surrounding the students. The research from Andreas and Deborah (2008) observing that the knowledge of mathematics is useful for and can be used in mathematics learning. From their research, Cecilia and Barbara (2007) saying that a special implication to support the research in mathematics teacher conception and their teaching and to the programmer of teacher education has been given. The research about the students' behavior in mathematics problem solving is identified in three cases namely naive or based on the real condition, routine and complex and it is connected with the problem of beginner and the expert (Beswick K et al, 2008).

Realistic Mathematics Education is one of the learning approach alternative that can be chosen by an elementary school teacher. This learning has developed in Indonesia since 2002 (Fauzan, 2002), that is developed by Freudenthal in Holland. Gravemeijer (1994: 82) saying that Realistic Mathematics Education is rooted in Freudenthal's interpretation of mathematics as an activity. It is said that mathematics is viewed as an activity, a way of working learning mathematics means doing mathematics, of which solving everyday life problem is an essensial part.

The research about the implementation of realistic mathematics learning approach at the elementary school students has been done many times by the teachers, lecturers, and the students of mathematics education, where one of the topics is done by the writer namely Round Number Operation (Christine K. Ekowati, 2006) and has an impact to increase the student's achievement in the concept. Purnama Dewi, a teacher in Ogan Ilir Regency, South Sumatra, also do a class action research by implementing PMRI at mathematics learning on the grade V students SDN Pemulutan in 2011, with an orientation at the increase of students learning activity.

One's intelligence in exact lessons especially mathematics and computation, doesn't always yield a human being useful for themselves and the state, since one is successful if they can build a good emotional relationship with themselves, other people and the surroundings, so that it is not only about the intelligence itself (Smart Parenting, 2011). The tendency of an intelligent student is that they do not have a good ability to associate with their friends, so that when they have been adult, they can be human being that do not have a big love to others and the environment.

The other concept using the real world is Contextual Teaching and Learning (CTL) where in mathematics the concept helping the teachers and the students relating the contain of mathematics lesson with a real world and motivating the students to make relationship between the knowledge and its implementation in their life as a member of a family, a member of a state and a laborer. There are four matters that is important namely: students, teacher, the process of learning and the teaching book. Jackson V. A. Tambelu and Viviani Regar writing (2010) writing that the composition of teaching book bases on CTL must be suitable with the surroundings, culture, work field and the context of daily life from the students. The result of the research concludes that (1) the draft of Senior High School teaching book with a contextual insight that is relevant to the students daily life in Minahasa Regency, North Sulawesi that has been developed after being revised by the research team based on the analysis is categorized good, (2) the product in the form of Senior High School teaching book with a contextual insight that is relevant to the students daily life in Minahasa Regency has been ready to be given the field test.

From the above elaboration, it can be said that the conservation of living space can be maintained by the high intelligent and aware human being where the awareness can not be got easily, but in a long time, as long as a generation life span. Both of formal and informal education is an exact place to develop the attitude, behavior and the 
positive awareness to the surroundings around them so that it can get intelligent human being cognitively that has a big love to the surroundings.

Based on the concept, the researcher is interested to develop the tools of mathematics learning based on environment by implementing the realistic mathematics learning approach at the elementary school especially at grade one and observe the influence on the increase o student's understanding about the mathematics concept that has an impact to the attitude of caring about the environment around them.

\section{Material and Method}

\section{A. Environment Knowledge Concept}

Knowledge can be said as a science (Hammado, 2013), if it can be elaborated systematically about the existence of the knowledge, and then what about the way to get it and it can show the utility for the human being and everything that has a very close relationship with it.

Basically knowledge of environment is a knowledge about the existence of our natural environmet, a knowledge about how to use our natural environment and a knowledge about how to take care of it. That is the reason that the environment knowledge for the elementary school students especially grade one is how many students can know about their natural environment, how far they can love their environment and they can build an attitude of conservating the natural environment around them.

Based on the concrete observation, the knowledge of environment about nature that should be had by the students grade one among others: (1) the students is aware that the big trees in the school is very important when they are in their playing session, (2) the students know how to take care of the plantations in the school by watering it and do not pick the leaves and flowers, (3) the students can keep the cleanliness of the school field by not throwing the rubbish anywhere, (4) the students can keep the cleanliness of the class by throwing the rubbish at the place that has been put before, (5) the students has known that they should not throw the rubbish in the school gutter since it will cause putrid odor and flood when the rain comes.

The natural knowledge is not a new matter for the students grade one since they have known it before when they are still in the kindergarten. Even they have known it when they do not go to school yet by observating their parents or their elder brothers/sisters cleaning their house, gutter, house yard and planting the trees. As an example is the program of planting the coconut trees by the governor of East Nusa Tenggara province in 2012 by distributing the seed to every kelurahan. The other example with the same goal is by distributing the seed of durian tree to every church from Diocese Kupang and it will be distributed later on to the leader of a household.

Those natural knowledge concepts will be the frame for mathematics concepts so that it will be a fresh, healthful, please learning and full of games.

\section{B. The Attitude Concept of Caring about Environment}

Basically attitude is an interrelation from various components (Tri Dayakisni, 2012), namely: (a) cognitive attitude formed based on the knowledge or information had by someone, (b) afective attitude relating with being happy or not being happy condition (c) connative attitude is someone's readiness to behave relating to object of attitude.

According to Dayakisni (2012), basically an attitude is not a character but a result of interaction between an individual with the environment so that the attitude is dynamic. The factor of experience has a big role in the attitude building. An attitude can be said as a result of learning as well, and that's why an attitude can change.

According to Mar'at (1981) there are some characterizations among others (a) the attitude based on evaluation concept relating to a certain object, arouse the motive to behave, (b) attitude is also described in various qualities and intensities that is different and move continuously from the positive one via a netral area toward the negative one, (c) attitude is looked upon more as a result of learning than as a result of development or something bequeathed, (d) attitude has a certain target, (e) the rank of attitude integrity is different, (e) attitude is relative permanent and do not change.

If we evaluate the change of attitude as a result of a learning process done by the teachers in the school, we can make a conclusion that a student is good or not. For an example by observing the student's habit in throwing the rubbish into the garbage as a process of learning done by the teacher. Maybe the attitude is developed or built by the habitual action in the student's family.

As we have known together that attitude is a desire or planning deriving from the students to choose or do something. A desire or a positive planning to help their friends, do not pick the flowers, throw the rubbish in its place will develop 
positive attitude in every student. Yet we still can not measure it since the attitude doesn't become an action, it is still a desire in their heart.

Then from the attitude shown by the students at interview test can be made a guide in observing how far a student's positive attitude after participating in the learning relating with their care about the living space around them.

\section{Thematic Learning Concept}

Thematic learning is an integrated learning using theme to relate some lessons so that it can give a deep experience to the students (Departement of Education, 2006). Theme is the key of the thought or the main idea that become the main discussion (Poerwadarminta, 1983). Thematic learning is more focused on the student's participation in the process of learning, so that the students can get a direct experience and able to get by themselves the various knowledges learnt. By the direct experience the students will understand the concepts they learn and relate it with the other concept that has been understood by them (Departement of Education, 2006).

Thematic learning as a concept can be viewed as an approach in learning that involving some lessons to give a meaningful experience to the students. It is said like that since in thematic learning, the students will understand the concepts they learn and relate it with the other concept that has been understood by them.

Based on some definitions above, it can be made a synthesis that thematic learning is a learning based on theme and focused more to the implementation of learning concept while doing something (learning by doing). Therefore, the teacher needs to design the learning experience that will influence its meaning for the students in learning. The learning experience showing the relation of the 115 conceptual elements that will make the process of learning more effective. The conseptual relation between the lessons learnt will make a scheme, so that the student will a get a holistic knowledge. Besides, by the implementation of thematic learning in the elementary school, the students will be helped, since it is suitable with their development step. This implementation stil observe everything as a whole.

\section{The Approach Concept of Realistic Mathematics Education (RME)}

Realistic mathematics learning is parable with Realistic Mathematics Education (RME), an approach of mathematics learning developed by Freudenthal in Holland. Gravemeijer (1994) explains that by looking at mathematics as an acticity thus learning mathematics means working with mathematics and the daily life problem solving is an important part in the learning. The other concept from realistic mathematics learning is given by Treffers (in Fauzan, 2002: 33 34) in the statement as follows,

The key idea of RME is that children should be given the opportunity to reinvent mathematics under the guidance of an adult (teacher). In addition, the formal mathematical knowledge can be developed from children's informal knowledge.

In the above statement Treffers (1994) explains the key concept of realistic mathematics learning that stresses on the need for the students to have the chances to get again mathematics with the adult help (teacher). Besides it is said that formal mathematics knowledge can be developed based on the informal knowledge had by the students. The statements above explains a point of view to mathematics learning that is put as a process for the students to find by themselves the knowledge of mathematics based on the informal knowledge had by them. In this point of view, mathematics is offered as not a 'mature' product that can be transfered by the teacher into the student's thought. In relation with the activity of mathematization in learning mathematics, Freudenthal in his book Mathematics as an Educational Task mentions two types of mathematization namely horizontal mathematization and vertical mathematization with an explain as follows,

"Horizontal mathematization involves going from the world of life into the world of symbol, while vertical mathematization means moving within the world of symbol".

The statement above explains that horizontal mathematization is about the process of real problem transformation / daily life problems into the symbol forms. Meanwhile the vertical mathematization is a process occurs in the scope of mathematics symbol itself. The example of horizontal mathematization is the problem identification, formulation and visualisation with a different way by the students. The example of vertical mathematization is the presentation of relation in the formulations, refine and make suitable the model of mathematics, the use of different models, the formulation of mathematics model and generalization.

Gravemeijer (1994 : 90) mentions the three principles namely (1) guided reinvention and progressive mathematizing (2) didactical phenomenology and (3) self-developed models. The description of each principle is as follows:

1. Guided reinvention and progressive mathematizing. According to Gravemijer (1994: 90), based on reinvention principle, the students must be given the chance to undergo the same process with the process when mathematics 
is found. The history of mathematics can be put as a source of inspiration in designing the lesson material. Besides, reinvention principle can be developed based on the procedure of informal problem solving. In this case the informal strategy can be understood to anticipate the procedure of informal problem solving. For the need a contextual problem should be found that can provide various procedures of problem solving and to indicate the route of learning beginning from the rank of learning mathematics as a real one to the rank of learning mathematics formally (progressive mathematizing).

2. Didactical phenomenology. Gravemeijer (1994: 90) says, based on this principle the presentation of mathematics topics in the realistic mathematics learning is presented based on two considerations namely (a) to show the various application that must be anticipated in the process of learning and (b) its suitability as a matter influencing in the process of progressive mathematizing.

3. Self-developed models, Gravemeijer (1994: 91) explains that based on this principle, when the students is solving the contextual problems, they are given the chance to develop their own model that functions as a bridge between the gap of informal knowledge and formal mathematics.

According to (1994: 169) discussion is a form of face to face teaching that is most common to be used to give the information, thought and idea to one another. Moreover in a discussion the learning process is not only the activity to recognize the information only but also enable the process of thinking well, with a synthesis and evaluation. Then we need to decise a form of discussion that will be done by considerating the real condition of the class. Since the learning is held in a class that is generally has a member of 40 until 44 students with a students position that is difficult to make a big group dicussion, thus the interaction among students is done via a small group discussion in pair beside of the class discussion. Based on the real condition of the class like described above and some characteristics and the principle of realistic mathematics learning, thus the steps of the learning done in this research contains of:

1. Understanding the contextual problem. In this step the teacher present the contextual problems to the students. Then the teacher asks the students to understand the problem earlier. The characteristics of the realistic mathematics learning shown in this step is using the context. The using of context can be viewed at the presentation of contextual problem as a point of departure of student's learning activity.

2. Explaining the contextual problem. This step is done when the students get difficulties to understand the contextual problem. In this step the teacher gives the aid by giving the instruction or enough questions that can guide them to understand the problems. The characteristics of realistic mathematics learning shown in this step is interactive, namely an interaction between the teacher and the students. Meanwhile the principle of guided reinvention at least has been shown when the teacher tries to give the guide to the students in understanding the problems.

3. Solving the contextual problem. In this step the students is pushed to solve the contextual problems individually based on their own capability by using the guidance that has been provided. The students has the freedom to use their own way. In the process of solving the problems, actually the students is asked or guided to get or construct the knowledge for themselve. In this step the teacher is enabled to give the aid (scaffolding) to the students who really need the aid. In this step, the two principles of realistic mathematics learning that can be shown is guided reinvention and progressive mathematizing and self-developed models. Meanwhile the characteristics that can be shown is the using of model. In solving the problems, the students have the freedom to build the model of the problems.

4. Comparing and discussing the answer. In this step at the early step the teacher asks the students to compare and discuss the answer with their friend. This discussion is a place for a pair of students to discuss their own answer. From this discussion it is hoped that the answer that is agreed by both of the students can be shown. Then the teacher asks the students to compare and discuss the answer that they have in the class discussion. In this step the teacher points or gives the chance to the pair of students to give their answer in front of the class and push the other students to elaborate and give the response that is shown in front of the class. The characteristics of realistic mathematics learning shown in this step is interactive and using the students contribution. The interaction can occur between the students and the students and also between the teacher and the students. In this discussion, the students' contribution is useful in the problem solving.

5. Concluding. From the result of class discussion the teacher guides the students to make a conclusion about the problem solving, concept, procedure or principle that has been built together. In this step the characteristics of realistic mathematics learning is interactive and using the student's contribution. 
Based on the elaboration about the above Realistic Mathematics Education, thus it can be concluded that the five characteristics of RME namely contextual, modeling, student's contribution, interactive and integrated is very appropriate to be implemented at the elementary school that is still in the step of thingking concretely, so that mathematics learning can be meaningful.

From the research's experience guiding the teacher grade one in the learning in the class, it is found that realistic approach is always needed in reaching the basic competence of Indonesian Language, Citizenship Education and Social Cultural and craft in order to make the students can be easy in understanding all the concepts given. That is the reason this real example in daily life and making optimal the knowledge about natural surroundings in thematic learning can use Realistic Education approach or RE.

\section{Method}

The type of research in this article is the research and developing with some steps namely (1) survey method to get early data that is a pre research, (2) method of development to develop the tools of mathematics learning based on the environment and (3) experiment method used to analyse the rate of mathematics knowledge, the environment knowledge and the attitude to love the student's environment after participating in the tool of learning developed.

Research and Development (R \& D), one of it is developed by Walter R. Borg dan Joyce P. Gall (1983 : 772 ), who define development research as follows:

Educational research and developmnet (R \& D) is a process used to develope and validate educational products. The steps of this process are usually referred to as the R \& D cycle, which consists of studying research findings pertinent to the product to be developed, developing the products based on these finding, field testing it in the setting where it will be used eventually, and revising it to correct the deficiencies found in the field-testing stage. In more rigorous programs of $\mathrm{R} \& \mathrm{D}$, this cycle is repeated until the field-test data indicate that the product meets its behaviourally defined objectives.

Research of education and development ( $\mathrm{R} \& \mathrm{D})$ is a process used to develop and validate the product of education. The steps of this process is usually named as a cycle of $\mathrm{R} \& \mathrm{D}$, consists of learning the result of the research relating the the product that will be developed, develop the product based on this result, a side of test in the regulation where finally it will be used and revise it to make better the lack found in the step of offering the test. In the tighter program from $\mathrm{R}$ $\& \mathrm{D}$, this cycle is repeated until the field of test data showing that the product fulfills the aim of the behaviour defined.

The approach used in this research is begun with an approach of research, development and will be finalized by the approach of experiment (Asikin \& Andi, 2004). In the research step, an early survey about the teaching material and the learning process used during this time. In the development step, the planning of mathematics teaching material developing based on the environment and the test problem of mathematics knowledge and the problem of attitude test toward the environment is done, where the development based on the need assesment that can be the product that will be developed. In the step of experiment, it is begun by giving the early test using the three of the test problem that has been valid and reliable and the last test at the last learning of first theme. From the early and last test, it is done a dependent $t$ different test since using the approach of pretest-postest one group. Generally the research method defined as a scientific way to get the valid data found, developed and proved a certain knowledge so that on its turn can be used to understand, solve and anticipate the problems in the education sphere (Putra, 2011). There are four key words that has to be viewed well namely (1) the scientific way that means this research activity based on the characterization of science, namely rasional (it is done with a way that is logically), empirically (can be observed by the senses of human being) and systematically (using the logical steps), (2) data got must be valid (level of accuracy) and reliable (level of consistency), (3) aim, where there are three aims of the research namely findings, development and autentication, (4) utility, namely this research is used to understand a problem.

In this research, R \& D method typed formative research is used that focused on two steps namely preliminary and formative evaluation step (Tessmer, 1993) consists of self evaluation, prototyping (expert reviews, one-to-one dan small group) and field test. From this formative type can be made the development model that is more efective, efficient, interesting, useful and can be acceptable.

The type of R \& D by Tessmer is almost the same with the type of R \& D according to Akker (1999) that is devided into two steps namely (1) preliminary study consists of preparation and development step and (2) formative study consists of evaluation and revision step. Preparation step using survey method namely curriculum analysis activity, the teacher analysis activity and learning analysis activity in the class. Meanwhile in the the development step, it is done a teaching material development planning with a format of taking the characteristics of Realistic Mathematics Education (RME) approach with a design as follows (suitable the book format published by PMRI): 


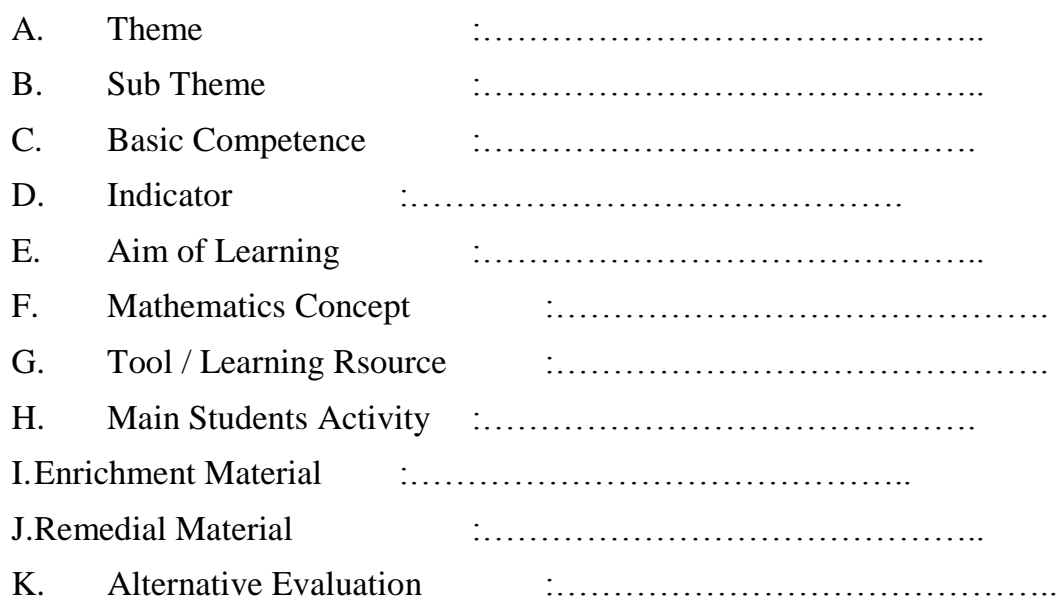

Note:

In this note, it will be written the material/ alternative media from local material that can be used by the teacher.

On the step of formative evaluation, it is used experiment method namely self evaluation, prototyping (expert reviews, one-to-one and small group) and field test. The experiment is done by comparing the condition before and after using the teaching material developed (before-after), such as shown in the foolowing picture:

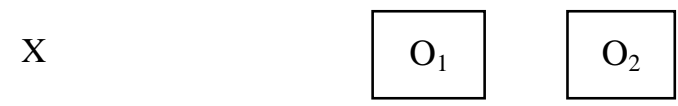

Where $\mathrm{O}_{1}$ is an understanding speed percentage, creativity and the result of learning before using the teaching material developed, meanwhile $\mathrm{O}_{2}$ is an understanding speed percentage, creativity and the result of learning after using the teaching material developed (Sugiyono, $2013: 415$ ). The effectiveness of using the learning tool developed is measured by comparing the score of $\mathrm{O}_{1}$ and $\mathrm{O}_{2}$.

\section{Result and Discussion}

The basic concept of the teaching material development in the form of student's book and teacher's guide book based on the result of need assesment done at the early of research. Based on curriculum 2013 for elementary school grade one, it is developed a teaching material suitable with the 4 themes namely the themes of Myself, My Hobby, My Activity and My family that is devided again to be 4 sub themes for each theme. Every teacher's and student's book is made for 16 meetings suitable with the 16 sub themes. The teacher's draft book and teacher's guide book is validated by 3 experts namely the expert of education, mathematics and environment with a result as follows:

Table 1. Recapitulation of product validation

\begin{tabular}{lllll}
\hline & Teacher's Guide Book & RPP & Student's Book & Test Problem \\
\hline Education Expert & 4,00 & 3,72 & 4,00 & 3,88 \\
Environment Expert & 3,74 & 3,80 & 3,74 & 3,25 \\
Mathematics Expert & 3,67 & 3,72 & 3,63 & 4,00
\end{tabular}

After being revised, it is done a limited try out at one of the classes in SD Inpres Naimata Kupang and a big class try out at two classes in SD Katolik St. Arnoldus Kupang that showing the level of teaching material practicality as follows:

Table 2. Recapitulation of product practicality

\begin{tabular}{lll}
\hline & Teacher's Book & Student's Book \\
\hline AGUSTINA BEDA TUPEN & $93,75 \%$ & $75 \%$ \\
SERAFINA KOA & $81,25 \%$ & $87,5 \%$ \\
TAROCI TALAK & $87,5 \%$ & $75 \%$ \\
\hline
\end{tabular}


Afterwards it is done a problem test of mathematics knowledge before and after using the teaching material developed to all the students and analysed with independent $t$ test. Meanwhile to observe the student's care or their attitude toward the surroundings around them it is used an instrument of attitude problem that is asked one by one by the teacher to all the students when they are in their rest. This activity is done before and after the using of teaching material developed and analysed like the test problem of mathematics ability. The recapitulation of analysis result in table is as follows:

Table 3. Recapitulation of dependent different test

\begin{tabular}{llll}
\hline & The score of $\mathbf{t}$ value & The score of $\mathbf{t}$ table & Decision \\
\hline Mathematics Knowledge & 3,42 & 2,08 & There is a difference \\
Environment Knowledge & 2,18 & 2,09 & There is a difference \\
Attitude of Caring about the Environment & 3,09 & 2,06 & There is a difference \\
\hline
\end{tabular}

To observe the effectiveness of the books developed, it is done an observation toward the student's activity and response during the learning by using the instrument that has been validated by the three experts above. The recapitulation of the result of student's activity and response during the learning is as follows:

Table 4. Student's activity

\begin{tabular}{ll}
\hline THEME & PERCENTAGE OF ACTIVITY \\
\hline MYSELF & $75 \%$ \\
MY HOBBY & $80 \%$ \\
MY ACTIVITY & $75 \%$ \\
MY FAMILY & $85 \%$ \\
\hline
\end{tabular}

Table 5. Student's response

\section{CRITERION OF RESPONSE}

Are You pleased of learning mathematics today?

Are You pleased of learning mathematics by using mathematics book with many pictures?

Are You pleased of learning mathematics while playing?

Are You pleased of learning mathematics in the school yard?

Are You pleased of counting the leaves falling at the school yard?

Are You pleased of counting the empty glasses of aqua at the school yard?

Are You pleased of the flowers at the school yard?

Have You ever thrown the leaves falling at the school yard to the garbage?

Have You ever thrown all the empty glasses of aqua that You see at the school yard to the garbage?

Have You ever counted all the flowers at the school yard?

\section{PERCENTAGE OF HAPPINESS / EVER}

$81,8 \%$

$90,9 \%$

$100 \%$

$77,3 \%$

$77,3 \%$

$72,7 \%$

$54,5 \%$

$81,8 \%$

$77,3 \%$

$40,9 \%$

Based on the result of recapitulation from table 1 until table 5, the product that is developed especially the student's book and the teacher's guide book has been valid, practical and effective to be used on the learning of elementary school grade one at the first semester. The test problem of student's attitude caring about the environment is especially done by interviewing directly every student when they are in playing time, done by 1 class teacher and 3 observers during 3 days respectively. Both of the teacher and observer read directly the problems and ask the students to choose 2 options namely agree or do not agree and the observer will make a sign at the answer chosen by the students. The same activity is done for one more time after the first theme of learning is finished.

Then the hypothesis to observe the difference of student's attitude caring about their environment is as follows:

$\mathrm{H}_{0}: \mu_{1}=\mu_{2}$ (there is no significant difference about the student's attitude before and after the treatment) 
$\mathrm{H}_{1}: \mu_{1} \neq \mu_{2}$ (there is a significant difference about the student's attitude before and after the treatment)

The t-tes calculation for the student's attitude caring about their surroundings is done by using SPSS program with an output interpretation as follows: (a) the number of students analysed is 25 namely as many as the students in class 1B, (b) the mean of early test score and final test score is 82,8 and 89,2 , (c) the interval of trust $95 \%$ between $-10,7$ and $-2,1$, (d) $t$ calculation 3,09 and (e) $t$ table 2,06. Then since the $t_{\text {value }}>t_{\text {table }}$ thus the hypotheses 0 is rejected or the alternative hypotheses is acceptable and valid vice versa. So that it can be concluded that there is a significant difference about the student's attitude of caring about the environment before and after using the tool of learning developed.

\section{Conclusion and Recommendation}

Based on the result, the discussion and some supporting theories, thus the conclusion is as follows: the development of thematic mathematics teacher teaching book based on environment using Realistic Mathematics Education approach, 11 songs supporting concept implantation and the real evaluation format or authentic assessment, a set of Rencana Pelaksanaan Pembelajaran (RPP) as many as 16 meetings suitable with the each sub theme, students book that is designed as Lembar Kerja Siswa (LKS) for 16 meetings, 10 package tools of mathematics visual aid as a medium in learning made from natural material around the school and domestic waste around the school is in valid category after being examined by the expert of education, environment and mathematics, and also practical after being done the limited class test by one model teacher and big class test by two model teacher and effective after the students activity in participating in the learning and their positive response classically being observated.

The books developed can increase the student's mathematics knowledge significantly, and can implant the attitude of loving the environment as early as possible to the students with a hope that they can build a behaviour of conservating their environment.

\section{Recommendation}

In order to make this development research can be continued for the shake of the students, the teacher at class 1and the headmeaster, thus the researcher give some recommendation as follows :

1. To do a development of a learning tool, we should make a need assessment that is suitable with the school physic, local culture, the students character and the teachers psychology.

2. To be a holistic learning, the teacher's book and the student's book for grade one semester 2 should be developed with a theme suitable with curriculum 2013.

3. Because of the attitude implantation of caring about the student's living space, the learning by optimizing the school environment will be very useful.

4. Realistic Education (RE) approach can be used as one of the approaches to get the basic competition of Bahasa Indonesia, PPKn (Pendidikan Kewarganegaraan) and SBDP (Sosial Budaya dan Prakarya).

5. It should be done a continuous guide between the teacher class one and the lecturer from FKIP Undana, in developing the learning medium that using the natural waste and local material.

6. It should be made a cooperation between Kementerian Pendidikan Nasional, Kementerian Lingkungan Hidup and Departemen Kehutanan to support the presence of the teacher guide book and thematic student's book based on the environment.

\section{References}

Agudelo Cecilia \& Clarke Barbara. (2007). Explanation of Attitude to Change: Colombian Mathematics Teachers Conception of The Crucial Determinants of Their Teaching Practices of Beginning Algebra. Journal of Mathematics Teacher Education, 10,-- May 2007.

Akker, Jan Van Den. (1999). Principles and Methods of Development Research. Universsity of Twente.

Aisyah, Nyimas. (2007). The Development of Mathematics Learning for Elementary School. High Education Directorate General of The Department of National education.

Asikin, M \& Cahyono, A.N. (2004). Research and Development in Education. Papers in Educational Research FMIPA Unnes.

Brundtland Harlem Gro et all. (1988). Our Collective Future. Gramedia Jakarta Incorporation Limited.

Dewi Purnama. (2011). The Implementation of Mathematics Learning using Realistic Education in Grade V SDN 27 Pemulutan. PTK Report. 
Ekowati K. Christine. (2008). The Implementation of Realistic Mathematics Education at Mathematics Learning at Grade V Students of SDK St. Arnoldus Penfui Kupang NTT. Science Media Journal, 6, July 2008.

Ekowati K. Christine. (2003). Minimalization of Student's Misconception at Mathematics Learning at Grade VII Students at SMPN 1 Kupang. PDM Research Report 2003.

Ekowati K. Christine. (2006). The Implementation of contextual Approach (CTL) for Round Number Learning at Grade VII Students at SMPN 1 Kupang NTT. PDM Research Report 2006.

Freudental, H. (1973). Mathematics as an Educational Task. Dordrecht: Reidel Publishing.

Freudental, H. -----. Why to Teach Mathematics so as to be Useful. Mathematisch Instituut der Rijksuniversiteit, Utrecht. NTHALEACH MATHEMATIC.

Gravemeijer, K. (1994). Developing Realistic Mathematics Education. Utrecht: Freudental Institute.

Gulo, W. (2002). Strategy of Learning and Teaching. Jakarta: Gramedia Jakarta Incorporation Limited.

Hidayati, Kana et. all. (2012). The Implementation of Mathematics Learning with an Environment Perspective Using Cooperative Approach to Develop a Friendly Attitude for the Environment and Raising the Result of Student's Learning. http://journal.uny.ac.id/index.php/pythagoras/article/view/685.

I Made Ardana. (2008). The Rise of Student's Quality Learning via Mathematics Learning Development with an Orientation of Cognitive Style and Constructive Perspective. Education Research and Development Journal, 1, April 2008.

Kemp, J.E. (1994). The Process of Teaching Design. Translated by: Asril Marjohan. Bandung: Bandung Institute of Technology.

Komariah. (2007). The solution Model via Realistic Approach at Elementary school Mathematics Learning. Basic Education Journal, V(7), - April 2007.

Muir T., Beswick K., Williamson J. (2008). I'm not very good at solving problems “An Exploration of Student's Problem Solving Behaviours". Journal of Mathematical Behaviours, 27, 2008. https://doi.org/10.1016/j.jmathb.2008.04.003

Murni Atma, Yusra Nurul, Soefitri Titi. (2010). The Implementation of Group Type Active Learning Method to Group Exchange (GGE) to Raise the Mathematics Learning Result at Grade X Social Science Students of State Senior High School 2 Pekanbaru Model. Education Research Journal, 11, October 2010.

Nugroho, Aryo. (2010). The Development of SMART Based Mathematics Learning Tool with TAI Strategy at Triangular Material Grade VII.

Novita Rita, Zulkardi, Hartono Yusuf. (2012). Exploring Primary Student's Problem Solving Ability by Doing Task Like PISA's Questions. IndoMS-Journal on Mathematics Education, 3, July 2012.

Nurul Chotimah. (2010). The Development of Learning Tool with a Set Vision of Coordination System Material. Semarang State University.

Pamungkas, Daud. (2012). Tellinga Story in relationship with Student's Character Education. Education View Journal, 2, Juny 2012.

Putra, N. (2011). Research and Developmnet. an Introduction. Jakarta : Raja Grafindo.

Styliamides J., Andreas \& Ball L., Deborah. (2008). Understanding and Describing Mathematical Knowledge for Teaching : Knowledge about Proof for Engaging Students in The Activity of Proving. Journal of Mathematics of Teacher Education, 11, August 2008. https://doi.org/10.1007/s10857-008-9077-9

Suharman. (2005). Cognitive Psychology. Srikandi.

Sarwono Wirawan Sarlito. (2002). Social Psychology. Balai Pustaka.

Sugiyono. (2013). Educational Research Methods. Alfabeta Bandung.

Tessmer, Martin. (1993). Planning and Conducting Formative Evaluations. Biddles Ltd, Guildford and King's Lynn.

Dayakisni, T. (2012). Social Psychology. KDT UNM Press.

Zulkardi. (2002). Developing A Learning Environment On Realistic Mathematics Education For Indonesian Student Teachers. PrintPartners Ipskamp - Enschede. 